\title{
Direct Estimate of Aromaticity with the Energy Decomposition Analysis
}

\author{
Israel Fernández ${ }^{*, a}$ and Gernot Frenking*,b \\ ${ }^{a}$ Departamento de Química Orgánica I, Facultad de Ciencias Químicas, Universidad Complutense Madrid, 28040, \\ Madrid, Spain \\ ${ }^{b}$ Fachbereich Chemie, Philipps-Universität Marburg, Hans-Meerwein-Strasse, D-35043 Marburg, Germany
}

\begin{abstract}
We discuss the results of selected projects where we estimate the strength of aromatic stabilization with the help of the Energy Decomposition Analysis within the Density Functional Theory framework. The paper introduces a new methodology to quantify the relative strength of aromaticity in aromatic and antiaromatic organic compounds. The approach is also useful for the study of homo(anti)aromatic systems and for compounds where the traditional methods do not give a consistent answer concerning their aromatic character such as small-ring compounds and metallabenzenes.
\end{abstract}

Keywords: Aromaticity, conjugation, energy decomposition analysis, DFT calculations.

\section{INTRODUCTION}

Aromaticity is an essential concept in chemistry which was introduced to account for the stability, reactivity, molecular structure, and other properties of many unsaturated organic compounds which was later extended to inorganic molecules and to saturated systems. In recent years, aromaticity has become a topic of renewed interest in experimental and theoretical research $[1,2]$. Numerous methods for qualitatively and quantitatively defining aromaticity were suggested which are based on energetic, geometric, electronic, magnetic, spectroscopic and other criteria [3]. The fuzzy nature of aromaticity is the reason that none of them is universal or free from ambiguities $[4,5]$. The difficulty to establish a universal aromaticity scale which is based on one single parameter is due to the multidimensional character of this phenomenon.

The difficulty to estimate the aromatic character of a compound lays in the fact that aromaticity has no precise meaning. In fact, it has been called a typical example for a unicorn of chemical bonding models, because everybody seems to know what it means although it is not an observable quantity [6]. In this report, we summarize our own efforts with the goal of directly estimating the strength of aromaticity of typical aromatic compounds and metallabenzenes. In our approach, we take the energy of the molecule as the fundamental property to derive a measure for the strength of aromaticity, because it was molecular energy which led chemists suggest that certain compounds are aromatic: i.e. the remarkably higher stability of certain cyclic $\pi$ conjugated compounds with respect to their corresponding acyclic analogues.

\footnotetext{
*Address correspondence to these authors at the Departamento de Química Orgánica I, Facultad de Ciencias Químicas, Universidad Complutense Madrid, 28040, Madrid, Spain; Tel: +34-913945155; Fax: +34-913944310; E-mail: israel@quim.ucm.es

Fachbereich Chemie, Philipps-Universität Marburg, Hans-MeerweinStrasse, D-35043 Marburg, Germany; Tel: +49-(0)6421-28-25563; Fax: +49-(0)6421-28-25566; E-mail: frenking@staff.uni-marburg.de
}

The crucial problem in estimating aromaticity is the choice of the acyclic reference compound which it is not unambiguous. Besides this problem, the calculation of the strength of the $\pi$ interactions in conjugated molecules is not trivial either. Very recently we suggested a method based on an energy decomposition analysis (EDA) which provides a quantitative measure for the strength of conjugation and hyperconjugation in cyclic and acyclic molecules [7-11]. One advantage of the method is that the calculated $\Delta \mathrm{E}_{\pi}$ values, which are used to estimate the strength of $\pi$-conjugation, are one component of the EDA which together with the other terms give the bond dissociation energy which is an observable quantity. Another advantage is, that the calculated values for the $\pi$-conjugation are directly estimated from the molecule without using external reference systems. It was found that the $\Delta \mathrm{E}_{\pi}$ values of meta and para substituted benzylic cations and anions correlate very well with experimentally derived Hammett $(\sigma)$ and Hammett-Brown $\left(\sigma^{+}\right.$and $\left.\sigma^{-}\right)$ substituent constants [8]. Our method has been successfully applied to the study of $\pi$-extended conjugated systems [9] where it was shown that the $\Delta \mathrm{E}_{\pi}$ values exhibit an excellent correlation with the trend of experimentally observable data such as ${ }^{13} \mathrm{C}$ NMR chemical shifts and bond length alternation [10]. The EDA can also be used to estimate the relative $\beta$ hyperconjugative effect of group 14-elements containing primary to tertiary cations [11]. Another advantage of the EDA derived data is the finding that the results are fairly insensitive to the functional and the basis sets which are used.

The good performance of this methodology to directly estimate the $\pi$-(hyper) conjugative strength encouraged us to use it for the study of $\pi$-aromaticity in typical organic compounds and in metallabenzenes. To this end, we compared the calculated $\Delta \mathrm{E}_{\pi}$ values of the cyclic compounds with appropriate acyclic reference systems. The corresponding $\Delta \Delta \mathrm{E}_{\pi}$ value defines the aromatic stabilizing energy (ASE) which can be considered as the extra-stabilizing energy due to the cyclic conjugation. As stated above, the choice of the adequate acyclic reference is problematic, because one may use (i) a molecule with the same number of multiple bonds or (ii) 
a molecule with the same number of conjugating $\sigma$ bonds as the cyclic system. It has been suggested that the latter choice of a reference system is favorable, because the ASE values exhibit a better correlation with Nuclear Independent Chemical Shift (NICS) values [12]. Therefore, we have used this approach to compute the ASE values with the EDA method. The results of this study are summarized here.

\section{THE ENERGY DECOMPOSITION ANALYSIS METHOD}

The EDA method [13] employs a systematic procedure to evaluate bonding energies. The strategy is to divide the molecule of interest, $\mathrm{AB}$, into fragments $\mathrm{A}$ and $\mathrm{B}$ which are then recombined in three separate steps in order to obtain the instantaneous interaction energy $\Delta E_{\text {int }}$.

In the first step of the EDA, the fragments $A$ and $B$ with their geometries frozen as in $\mathrm{AB}$ are computed individually in appropriately-selected electronic states (which may not be the ground states). The fragment A and B are then superimposed with unrelaxed electron densities at the geometry of $\mathrm{AB}$ to give $\mathrm{A}^{\prime} \mathrm{B}$ '. This gives the quasiclassical electrostatic interaction, $\Delta E_{\text {elstat }}$, as the energy difference between the original $\mathrm{AB}$ and $\mathrm{A}^{\prime} \mathrm{B}$ ' in its frozen electronic state. The superposition usually lowers the energy because the total nuclear-electron attraction in most cases is larger than the sum of the nuclear-nuclear and electron-electron repulsion [14] However, the resulting product wavefunction for this modified A'B' species violates the Pauli principle because electrons with the same spin may occupy the same spatial region. This situation is rectified in the second step of the EDA by antisymmetrization and renormalization of the A'B' wavefunction thereby removing electron density, particularly from the A-B bonding region, where the overlap of the frozen densities is large. This step gives the Pauli repulsion term, $\Delta E_{\text {Pauli }}$. The molecular orbitals are relaxed in the final step of the EDA. This allows the occupied and vacant orbitals to mix. The resulting electron delocalization gives the stabilizing orbital interaction term, $\Delta E_{\text {orb }}$, which may be used as estimate for the strength of the covalent interactions.

The total interaction energy, $\Delta E_{\mathrm{int}}$, is thus the sum of the three terms:

$\Delta E_{\text {int }}=\Delta E_{\text {elstat }}+\Delta E_{\text {Pauli }}+\Delta E_{\text {orb }}$

Note that $\Delta E_{\text {int }}$ is not the same as a bond dissociation energy $\left(D_{\mathrm{e}}\right)$ of A-B, because the fragments A and B have not been calculated at their equilibrium geometry and perhaps not in the electronic ground state. The additional energy which is related to the geometric relaxation of the A and $\mathrm{B}$ fragments is the preparation energy $\Delta E_{\text {prep }}$ term [13]. The bond dissociation energy is calculated according to equation 2 :

$-D_{\mathrm{e}}=\Delta E_{\text {prep }}+\Delta E_{\text {int }}$

The $\Delta E_{\text {orb }}$ term can be dissected into contributions from orbitals which belong to different irreducible representations of the point group of the molecule. If a molecule has mirror symmetry, the $\Delta E_{\text {orb }}$ term has contributions which come from $\sigma\left(\Delta E_{\sigma}\right)$ or $\pi\left(\Delta E_{\pi}\right)$ orbital contributions. The $\pi$ term is crucial for the present study, since the $\Delta E_{\pi}$ contribution provides a direct measure of the strength of $\pi$ (hyper)conjugation in a molecule without recourse to external reference systems [7-11]. For this reason, we only show the $\Delta E_{\pi}$ values necessary for the calculation of the ASE values in this report. Further details regarding the EDA method can be found in the literature [13].

All calculations reported herein have been carried out using the ADF program package [15]. The geometries of the molecules were optimized at the gradient corrected DFT level of theory using Becke's exchange functional [16] in conjunction with Perdew's correlation functional [17] (BP86). Uncontracted Slater-type orbitals (STOs) were employed as basis functions in SCF calculations [18]. Triple- $\zeta$ quality basis sets were used, which were augmented by two sets of polarization functions, that is, $\mathrm{p}$ and $\mathrm{d}$ functions for the hydrogen atom and $\mathrm{d}$ and $\mathrm{f}$ functions for the other atoms. This level of theory is denoted as BP86/TZ2P. An auxiliary set of s, p, d, f, and g STOs was used to fit the molecular densities and to represent the Coulomb and exchange potentials accurately in each SCF cycle [19]. Scalar relativistic effects were considered using the zero-order regular approximation (ZORA) [20].

1. Aromaticity in Main Group Reference Compounds: Benzene, Group-15 Heterobenzenes $\mathrm{C}_{5} \mathrm{H}_{5} \mathrm{E}(\mathrm{E}=\mathrm{N}-\mathrm{Bi})$ and Five-Membered Aromatic Compounds $\mathrm{C}_{4} \mathrm{H}_{4} \mathrm{E}(\mathrm{E}=$ $\mathrm{O}, \mathrm{NH}, \mathrm{S})[21]$

In order to estimate the ASE values in the six-membered cyclic systems, we calculated the interactions between three $\mathrm{C}_{2} \mathrm{H}_{2}$ fragments in benzene and between two $\mathrm{C}_{2} \mathrm{H}_{2}$ moieties and one ECH fragment in the heterobenzenes $\mathrm{C}_{5} \mathrm{H}_{5} \mathrm{E}$. The fragments were calculated as open-shell singlets with two unpaired electrons in $\sigma$ orbitals. This approach gives the cyclic $\pi$ conjugation in the molecules. Chart 1 schematically shows the electronic structure of the fragments which were used for the EDA calculations.

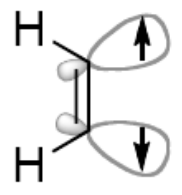

\section{$\left(3 \mathrm{C}_{2} \mathrm{H}_{2}\right.$, open-shell singlet)}

Chart 1. Fragments used in the EDA calculations.

The strength of the $\pi$ conjugation in the cyclic systems shown in Table 1 shall be compared with the calculated $\pi$ conjugation in the acyclic reference systems 1,3,5,7-alltrans-octatetraene for benzene and the related hetero systems $\mathrm{CH}_{2}(\mathrm{CH})_{4} \mathrm{ECHCH}_{2}(\mathrm{E}=\mathrm{N}-\mathrm{Bi})$ for comparison with the heterobenzenes. The acylic systems have been chosen because they have the same number of $\pi$ conjugations over a single bond than the cyclic systems as recommended by Mo and Schleyer [12]. The ASE values which are calculated as differences between the strength of the $\pi$ conjugation in the cyclic compounds and the acyclic reference system suggest that pyridine has a slightly larger aromatic $\pi$ stabilization $(45.7 \mathrm{kcal} / \mathrm{mol})$ than benzene $(42.5 \mathrm{kcal} / \mathrm{mol})$. The heavier heterobenzenes are less stabilized by cyclic $\pi$ conjugation but the ASE values are still rather large (Table 1). Note that there is a steady decrease of the aromaticity strength given by the ASE values when the group- 15 elements become heavier. This result is in contrast with the work by Shobe who reported, using NICS values, that there is a nearly con- 
Table 1. EDA Results for Six-Membered Aromatic Compounds at BP86/TZ2P. Energy Values in kcal/mol.

\begin{tabular}{|c|c|c|c|c|c|c|}
\hline$\Delta \mathbf{E}_{\pi}^{a}$ & $\begin{array}{l}-107.7 \\
(9.3 \%)\end{array}$ & $\begin{array}{l}-113.5 \\
(8.8 \%)\end{array}$ & $\begin{array}{l}-101.3 \\
(9.1 \%)\end{array}$ & $\begin{array}{c}-97.8 \\
(9.2 \%)\end{array}$ & $\begin{array}{c}-94.8 \\
(9.3 \%)\end{array}$ & $\begin{array}{c}-93.6 \\
(9.4 \%)\end{array}$ \\
\hline $\mathbf{A S E}^{\mathbf{b}}$ & 42.5 & 45.7 & 36.9 & 34.9 & 31.1 & 29.4 \\
\hline \multicolumn{7}{|c|}{ Reference } \\
\hline & $\mathrm{E}=\mathrm{CH}$ & $\mathrm{E}=\mathrm{N}$ & $E=P$ & $\mathrm{E}=\mathrm{As}$ & $\mathrm{E}=\mathrm{Sb}$ & $\mathrm{E}=\mathrm{Bi}$ \\
\hline$\Delta \mathbf{E}_{\pi}^{a}$ & $\begin{array}{c}-65.2 \\
(6.3 \%)\end{array}$ & $\begin{array}{c}-67.8 \\
(6.2 \%)\end{array}$ & $\begin{array}{c}-64.4 \\
(7.0 \%)\end{array}$ & $\begin{array}{c}-62.9 \\
(7.1 \%)\end{array}$ & $\begin{array}{c}-63.7 \\
(7.4 \%)\end{array}$ & $\begin{array}{c}-64.2 \\
(7.6 \%)\end{array}$ \\
\hline
\end{tabular}

${ }^{\mathrm{a}}$ The percentage values in parentheses give the contribution to the total orbital interactions $\Delta \mathrm{E}_{\mathrm{orb}}$.

${ }^{b}$ romatic stabilization energy given by the difference between the $\Delta \mathrm{E}_{\pi}$ values of the cyclic molecule and the acyclic reference compound.

stant degree of aromaticity in the entire series from pyridine to bismin [22].

Another class of compounds which are classical examples of aromatic systems are the five-membered heterocyclic systems pyrrole, furane and thiophene. Table 2 gives the $\mathrm{EDA}-\Delta E_{\pi}$ values for the 5-membered cyclic compounds together with the theoretical data for the acylic conjugated reference systems $\mathrm{CH}_{2}(\mathrm{CH})_{3} \mathrm{ECHCH}_{2}(\mathrm{E}=\mathrm{NH}, \mathrm{O}, \mathrm{S})$.

The conjugation between the $\mathrm{C}=\mathrm{C}$ moieties and atom $\mathrm{E}$ $(\mathrm{NH}, \mathrm{O}, \mathrm{S})$ in the heterocyclic compounds is calculated to be larger for $\mathrm{E}=\mathrm{NH}(-98.0 \mathrm{kcal} / \mathrm{mol})$ than for the group 6 systems with $\mathrm{E}=\mathrm{O}(-77.7 \mathrm{kcal} / \mathrm{mol})$ and $\mathrm{E}=\mathrm{S}(-77.6 \mathrm{kcal} / \mathrm{mol})$. The extra aromatic stabilizations in pyrrole $(21.1 \mathrm{kcal} / \mathrm{mol})$ and thiophene $(21.9 \mathrm{kcal} / \mathrm{mol})$ given by the EDA have a similar strength while the ASE of furane $(16.2 \mathrm{kcal} / \mathrm{mol})$ is weaker than in the former compounds. A similar trend has been found using the Block-Localized Wavefunction (BLW) method [12] thus supporting the ability of the EDA-method to estimate the strength of $\pi$-aromaticity.

\section{Homoaromatic, Homoantiaromatic and Antiaromatic Compounds}

We calculated carbocyclic compounds where the conjugation between double bonds is hindered by one or two satu- rated $\mathrm{CH}_{2}$ groups. There is still hyperconjugation between the $\pi$ orbitals which can induce weak homoaromaticity or homoantiaromaticity. We want to point out that a $\mathrm{CH}_{2}$ group in planar cyclic systems such as cyclopropene and cyclobutene has two $\pi$ electrons. This means that cyclopropene is formally a homoantiaromatic molecule because it has four $\pi$ electrons while cyclobutene is a $6 \pi$ homoaromatic compound. Besides homoaromatic and homoantiaromatic molecules, we also present the strength of the $\pi$ conjugation in the archetypical antiaromatic molecule 1,3-cyclobutadiene. The EDA results of the cyclic compounds and their acyclic reference systems are given in Table 3.

The EDA results in Table 3 show that the $\pi$ conjugation in the homoconjugated and antiaromatic systems is as expected much weaker than in the previous aromatic compounds. The largest value for the hyperconjugation in the odd-membered cyclic compounds is calculated for homoaromatic 1,3 -cyclopentadiene $(-21.3 \mathrm{kcal} / \mathrm{mol})$ while the $\Delta E_{\pi}$ values in the homoantiaromatic molecules cyclopropene $(-14.0 \mathrm{kcal} / \mathrm{mol})$ and 1,3,5-cycloheptatriene $(-19.1 \mathrm{kcal} / \mathrm{mol})$ are slightly smaller. The difference between homoaromaticity and homoantiaromaticity comes to the fore when the ASE values are compared. There are negative ASE values for the $4 \pi$ compound cyclopropene $(-2.9 \mathrm{kcal} / \mathrm{mol})$ and for the $8 \pi$

Table 2. EDA Results for Pentagonal Heteroaromatic Compounds at BP86/TZ2P. Energy Values in kcal/mol.

\begin{tabular}{|c|c|c|c|}
\hline Molecule & 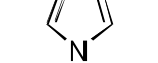 & & 4 \\
\hline$\Delta \mathbf{E}_{\pi}^{a}$ & $-98.0(8.1 \%)$ & $-77.7(6.8 \%)$ & $-77.6(8.5 \%)$ \\
\hline \multirow[t]{2}{*}{$\mathbf{A S E}^{\mathbf{b}}$} & 21.1 & 16.2 & 21.9 \\
\hline & $\mathrm{E}=\mathrm{NH}$ & $\mathrm{E}=\mathrm{O}$ & $\mathrm{E}=\mathrm{S}$ \\
\hline$\Delta \mathbf{E}_{\pi}^{\mathrm{a}}$ & $-76.9(6.7 \%)$ & $-61.5(5.5 \%)$ & $-55.7(6.3 \%)$ \\
\hline
\end{tabular}

${ }^{\text {a }}$ The percentage values in parentheses give the contribution to the total orbital interactions $\Delta \mathrm{E}_{\mathrm{orb}}$.

${ }^{\mathrm{b}}$ Aromatic stabilization energy given by the difference between the $\Delta \mathrm{E}_{\pi}$ values of the cyclic molecule and the acyclic reference compound. 
Table 3. EDA Results for Homoaromatic and Antiaromatic Compounds at BP86/TZ2P. Energy Values in kcal/mol.

\begin{tabular}{|c|c|c|c|c|c|c|}
\hline $\begin{array}{l}\text { Mole- } \\
\text { cule }\end{array}$ & $\Delta$ & $\sqrt{1}$ & & & & \\
\hline$\Delta \mathbf{E}_{\pi}^{a}$ & $\begin{array}{c}-14.0 \\
(3.7 \%)\end{array}$ & $\begin{array}{c}-20.0 \\
(4.6 \%)\end{array}$ & $\begin{array}{l}-35.4 \\
(3.8 \%)\end{array}$ & $\begin{array}{c}-41.4 \\
(4.4 \%)\end{array}$ & $\begin{array}{c}-52.8 \\
(4.4 \%)\end{array}$ & $\begin{array}{c}-9.6 \\
(2.6 \%)\end{array}$ \\
\hline $\mathbf{A S E}^{\mathrm{b}}$ & -2.9 & 3.5 & -1.5 & 4.2 & -6.5 & -31.9 \\
\hline$\Delta \mathbf{E}_{\pi}^{a}$ & $\begin{array}{c}-16.9 \\
(3.0 \%)\end{array}$ & $\begin{array}{c}-16.5 \\
(2.3 \%)\end{array}$ & $\begin{array}{l}-36.9 \\
(3.9 \%)\end{array}$ & $\begin{array}{c}-37.2 \\
(3.9 \%)\end{array}$ & $\begin{array}{c}-59.3 \\
(4.7 \%)\end{array}$ & $\begin{array}{c}-41.5 \\
(6.3 \%)\end{array}$ \\
\hline
\end{tabular}

${ }^{\mathrm{a}}$ The percentage values in parentheses give the contribution to the total orbital interactions $\Delta \mathrm{E}_{\text {orb }}$.

${ }^{\mathrm{b}}$ Aromatic stabilization energy given by the difference between the $\Delta \mathrm{E}_{\pi}$ values of the cyclic molecule and the acyclic reference compound.

system $1,3,5$-cycloheptatriene $(-6.5 \mathrm{kcal} / \mathrm{mol})$ while the $6 \pi$ molecule 1,3-cyclopentadiene has a positive ASE value (4.2 $\mathrm{kcal} / \mathrm{mol})$.

Homoconjugation along the $\mathrm{CH}_{2} \mathrm{CH}_{2}$ group in the $6 \pi$ compound cyclobutene $(-20.0 \mathrm{kcal} / \mathrm{mol})$ is stronger than in the $8 \pi$ compound 1,3 -cyclohexadiene $(-18.6 \mathrm{kcal} / \mathrm{mol})$. The calculated ASE values for the former compound (3.5 $\mathrm{kcal} / \mathrm{mol})$ and for the latter $(-1.5 \mathrm{kcal} / \mathrm{mol})$ indicate that the $4 n+2$ pattern also holds for these homoconjugated systems. Comparison of the $\pi$ hyperconjugation strength in the homoaromatic $6 \pi$ compound cyclobutene $(-20.0 \mathrm{kcal} / \mathrm{mol})$ with the $\pi$ conjugation of one $\mathrm{C}=\mathrm{C}$ group in benzene $(-73.5$ $\mathrm{kcal} / \mathrm{mol}$ ) indicates that hyperconjugation may not be negligible. The strongly antiaromatic character of 1,3cyclubutadiene becomes strikingly obvious from the large negative ASE value $(-31.9 \mathrm{kcal} / \mathrm{mol})$.

From the above data it becomes clear that our EDAbased approach provides a useful energy scale for the strength of aromaticity which can be used to classify compounds according to their relative ASE values. Compounds with ASE > 0 can be considered as aromatic (the highest ASE values were computed for benzene and pyridine, ca. 45 $\mathrm{kcal} / \mathrm{mol}$ ), whereas antiaromatic compounds exhibit highly negative ASE values. Compounds with small positive ASE values are typical for homoaromatic compounds while small negative ASE values are indicative of homoantiaromaticity.

3. Aromaticity in Neutral Exocyclic Substituted Cyclopropenes $(\mathrm{HC})_{2} \mathrm{C}=\mathrm{E}\left(\mathrm{E}=\mathrm{BH}\right.$ to $\mathrm{InH}$ (group 13), $\mathrm{CH}_{2}$ to $\mathrm{SnH}_{2}$ (group 14), NH to $\mathrm{SbH}$ (group 15), $\mathrm{O}$ to Te (group 16)

Once the new scale of aromaticity given by the ASE values of the EDA calculations was established, we were interested in to what extent different exocyclic $(\mathrm{C}=\mathrm{X})$ substituents induce aromaticity and anti-aromaticity in cyclopropene derivatives $(\mathrm{HC})_{2} \mathrm{C}=\mathrm{X}[23]$. The consensus opinion suggests that parent methylenecyclopropene, $(\mathrm{HC})_{2} \mathrm{C}=\mathrm{CH}_{2}$, the simplest cross-conjugated cyclic hydrocarbon, is non-aromatic based both on experimental observations [24] and theoretical analysis. On the other hand, various criteria agree that cyclopropenone is at least modestly aromatic [24-26]. However, quantitative assessments of the aromaticity of other $(\mathrm{HC})_{2} \mathrm{C}=\mathrm{X}$ derivatives have not led to satisfactory agreement. Thus, this family of compounds represents a para- mount opportunity to use the EDA-aromaticity method. Our results in combination with BLW and NICS calculations give a definitive answer to a question which has been controversially discussed in the literature for several decades.

Exocyclic substituents have a strong influence on the aromaticity/antiaromaticity of methylene cyclopropene derivatives, $(\mathrm{HC})_{2} \mathrm{C}=\mathrm{X}$. More electronegative substituents, e.g. $\mathrm{X}=\mathrm{O}$, polarize the exocyclic double bond away from three membered ring (3MR), which then resembles the (aromatic) $2 \pi$ electron cyclopropenylium cation (see Scheme 1). More electropositive substituents, e.g., $\mathrm{X}=\mathrm{InH}$, behave in the opposite way and polarize the exocyclic double bond toward the $3 \mathrm{MR}$, which then resembles the (antiaromatic) $4 \pi$ electron cyclopropenylium anion (Scheme 1). The computed ASE values are in the range between -26 and $8 \mathrm{kcal} / \mathrm{mol}$.

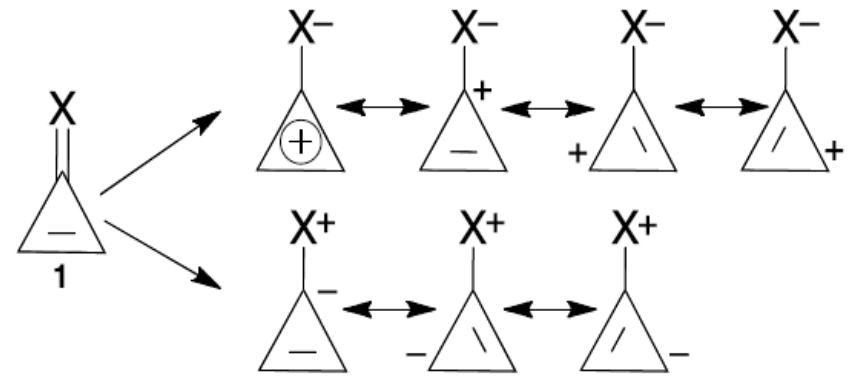

Scheme 1. Resonance contributors of polarized methylenecyclopropene derivatives. The aromatic $2 \pi$ electron character is emphasized by the circle notation, in contrast to the anti-aromatic $4 \pi$ electronic structure.

Within each period, 3MRs with exocyclic group 16 substituents have more positive (or less negative) EDA-ASE values and are more aromatic. Those with group 13 substituents have more negative EDA-ASE values and are generally anti-aromatic. Additionally, the ASEs interval of the $3 \mathrm{MRs}$ is roughly equal among those having substituents from group-14 to group-15 to group-16 atoms. Systems which possess group 13 substituents have much smaller ASEs, which can be ascribed to relatively strong $\sigma_{\mathrm{CH}}$ or $\sigma_{\mathrm{CC}} \rightarrow \mathrm{pX}$ (vacant) hyperconjugation in the acyclic reference molecules. The trend of the ASE values for the $3 \mathrm{MRs}$ is displayed in Fig. (1). There is a steady decrease of the ASE values within a group and within each row when the atom becomes less electronegative. 


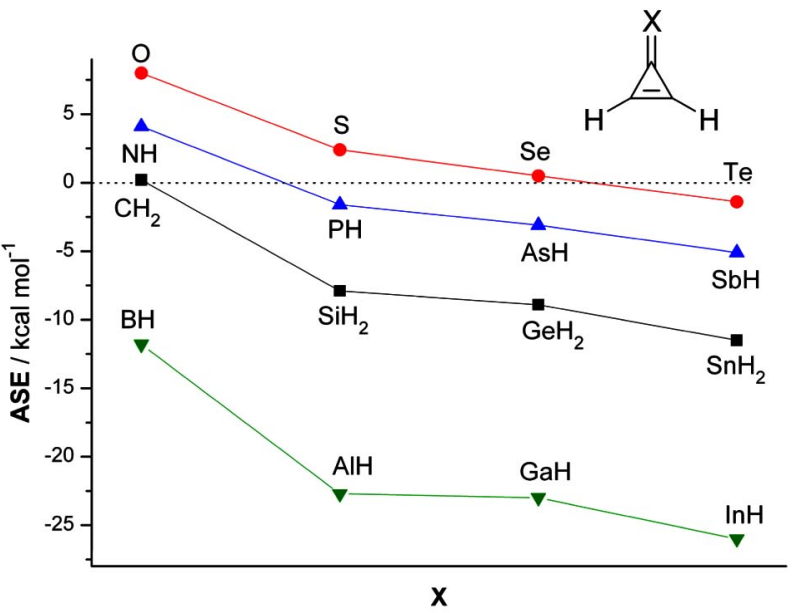

Fig. (1). Calculated EDA-ASE values for $(\mathrm{HC})_{2} \mathrm{C}=\mathrm{X}(\mathrm{X}=\mathrm{BH}$ to $\mathrm{InH}$ (group 13), $\mathrm{CH}_{2}$ to $\mathrm{SnH}_{2}$ (group 14), $\mathrm{NH}$ to $\mathrm{SbH}$ (group 15), and $\mathrm{O}$ to $\mathrm{Te}$ (group 16).

As readily seen in Fig. (1), the aromaticity of exocyclic substituted cyclopropenes $(\mathrm{HC})_{2} \mathrm{C}=\mathrm{X}$ is very sensitive to the nature of the substituents. Exocyclic substituted cyclopropenes with electronegative substituents have positive ASE values and thus, they are aromatic resembling the $2 \pi$ electron cyclopropenium cation. On the other hand, exocyclic substituted cyclopropenes with electropositive substituents have negative ASE values and they can be considered as antiaromatic species resembling the $4 \pi$ electron cyclopropenium anion. The calculations indicate that $(\mathrm{HC})_{2} \mathrm{C}=\mathrm{O}$ and $(\mathrm{HC})_{2} \mathrm{C}=\mathrm{InH}$ are the most aromatic and most antiaromatic species in our set of compounds.

\section{Aromaticity in Metallabenzenes}

Metallabenzenes are six-membered cyclic molecules derived from benzene where one $\mathrm{CH}$ moiety is replaced by an isolobal transition-metal fragment. It is a class of compounds which was theoretically predicted as stable species in 1979 by Thorn and Hoffman [27]. The first metallabenzene could become synthesized in 1982 by Roper et al. [28]. Numerous neutral and charged metallabenzenes have been isolated in the last three decades where new species can be expected to become synthesized in the future [29].

The question about the aromatic character of metallabenzenes received little attention from theory in the past [30]. An early work by Chamizo et al. [30a] suggested that iridabenzene should not be considered as aromatic but two more recent studies by Martin and coworkers [30b] and by de Proft and Geerlings [30c] came to different conclusions about the aromaticity in metallabenzenes. The proposed aromatic nature of metallabenzenes is supported by different experimental observations, i.e. most metallabenzenes exhibit deshielded proton resonances in their ${ }^{1} \mathrm{H}-\mathrm{NMR}$ spectrum, bond lengths equalization, and ring planarity [29]. The chemical reactivity of metallabenzenes is also in agreement with the classification as aromatic species. They undergo typical reactions of aromatic compounds, such as electrophilic aromatic substitution or formation of arene complexes. However, metallabenzenes may also engage in reactions which are unusual for aromatic systems such as cycloaddition or cyclopentadienyl complex formation, which suggests that metallacycles are not as aromatic as their all-carbon analogues [29].

The conflicting observations about the chemical behavior of metallabenzenes as aromatic species let us carry out a

Table 4. EDA results for metallabenzenes at BP86/TZ2P. Energy values in $\mathrm{kcal} / \mathrm{mol}$.

\begin{tabular}{|c|c|c|c|c|c|c|c|}
\hline Molecu & 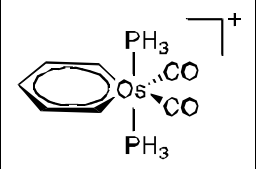 & $\sum_{\substack{\mathrm{PH}_{3} \\
\mathrm{Ru}_{-}^{-} \cdot \mathrm{CO}}}^{\mathrm{PH}_{3}}$ & 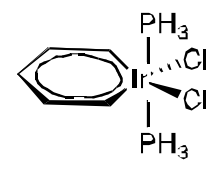 & $\left.\sum_{\substack{\mathrm{PH}_{3} \\
\mathrm{NCMe}}}^{\mathrm{PH}_{3}}\right]^{2+}$ & 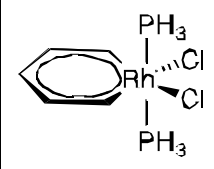 & & \\
\hline $\begin{array}{l}\text { Com- } \\
\text { pound }\end{array}$ & 1 & 2 & 3 & 4 & 5 & 6 & 7 \\
\hline \multirow[t]{2}{*}{$\Delta \mathbf{E}_{\pi}{ }^{a}$} & -97.5 & -97.5 & -97.2 & -103.3 & -97.1 & -100.1 & -97.3 \\
\hline & $(10.1 \%)$ & $(10.3 \%)$ & $(9.7 \%)$ & $(10.3 \%)$ & $(10.0 \%)$ & $(10.2 \%)$ & $(10.2 \%)$ \\
\hline $\mathbf{A S E}^{\mathbf{b}}$ & 17.6 & 17.7 & 33.5 & 8.7 & 33.4 & 37.6 & 32.8 \\
\hline \multirow[t]{2}{*}{$\Delta \mathbf{E}_{\pi}^{a}$} & -79.9 & -79.8 & -63.7 & -94.6 & -63.7 & -62.5 & -64.5 \\
\hline & $(9.0 \%)$ & $(9.2 \%)$ & $(7.2 \%)$ & $(10.1 \%)$ & $(7.6 \%)$ & $(6.8 \%)$ & $(7.8 \%)$ \\
\hline
\end{tabular}

${ }^{\text {a }}$ The percentage values in parentheses give the contribution to the total orbital interactions $\Delta \mathrm{E}_{\mathrm{orb}}$.

${ }^{\mathrm{b}}$ Aromatic stabilization energy given by the difference between the $\Delta \mathrm{E}_{\pi}$ values of the cyclic molecule and the acyclic reference compound. 
systematic theoretical study using the EDA where we addressed the aromaticity and bonding situation in 21 different metallabenzenes including $4 \mathrm{~d}$ and $5 \mathrm{~d}$ transition metals (metal $=\mathrm{Os}, \mathrm{Ru}, \mathrm{Ir}, \mathrm{Rh}, \mathrm{Pt}$, and Pd) [31]. We found that the experimentally observed larger stability of $5 \mathrm{~d}$ complexes compared with $4 \mathrm{~d}$ species is not related to the strength of the $\pi$ conjugation. The lower metal- $\mathrm{C}_{5} \mathrm{H}_{5}$ binding energy of the $4 \mathrm{~d}$ complexes correlates rather with weaker $\sigma$-orbital interactions. The comparison between the strength of the $\pi$ bonding in the metallacyclic compounds with appropriate acyclic reference molecules indicates that metallabenzenes should be considered as aromatic compounds whose extra stabilization due to aromatic conjugation is weaker, however, than in benzene. A selection of some EDA results of our work [31] is given in Table 4. The calculated ASE values span a range from 8.7 $\mathrm{kcal} / \mathrm{mol}$ for complex $\mathbf{4}$ and $37.6 \mathrm{kcal} / \mathrm{mol}$ for $\mathbf{6}$ which is nearly as aromatic as benzene (ASE $=42.5 \mathrm{kcal} / \mathrm{mol}$ ). The classical metallabenzene model compounds $\mathbf{5}$ and $\mathbf{1}$ exhibit intermediate aromaticity with ASE values of $33.4 \mathrm{kcal} / \mathrm{mol}$ and $17.6 \mathrm{kcal} / \mathrm{mol}$ which is comparable to the values in heteroaromatic organic compounds (see above).

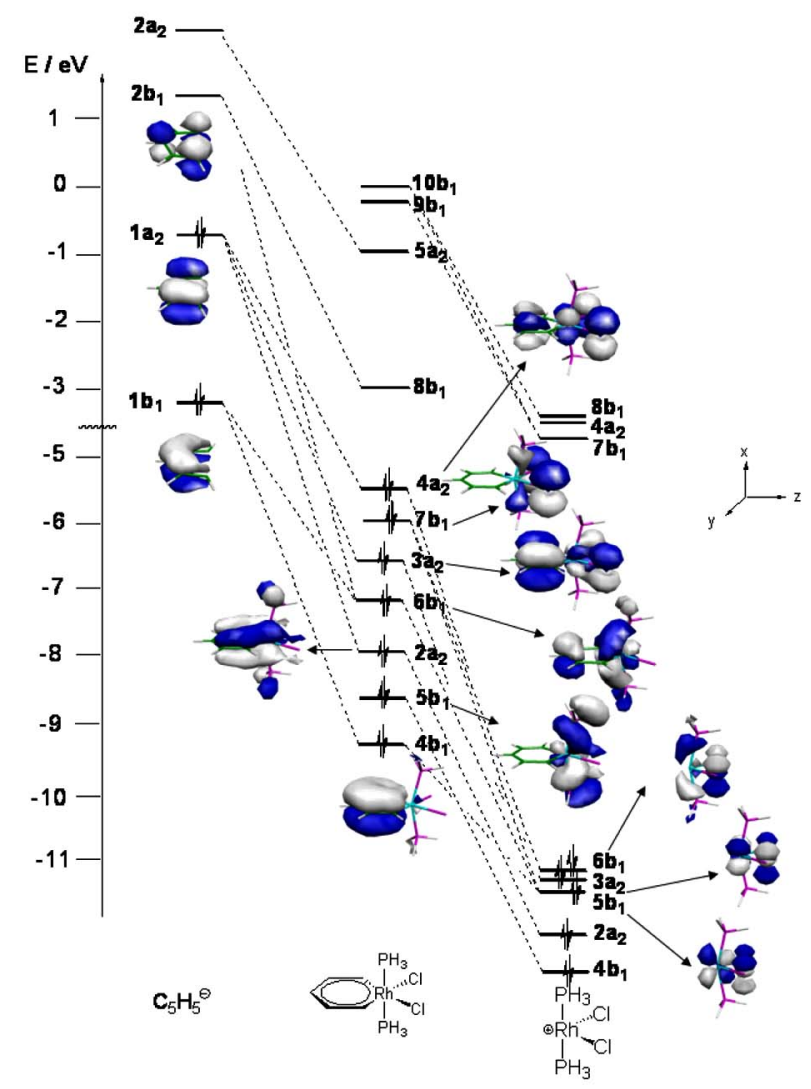

Fig. (2). Plot of the valence $\pi$ orbitals of $\left[\left(\mathrm{C}_{5} \mathrm{H}_{5}\right) \mathrm{Rh}\left(\mathrm{PH}_{3}\right)_{2}(\mathrm{Cl})_{2}\right](5)$ and the $\pi$ orbitals of the fragments $\mathrm{C}_{5} \mathrm{H}_{5}{ }^{-}$and $\left[\mathrm{Rh}\left(\mathrm{PH}_{3}\right)_{2}(\mathrm{Cl})_{2}\right]$ in the frozen geometry of $\mathbf{5}$. The value of the outermost contour line is 0.035 .

We also analyzed the electronic structure of metallabenzenes in more detail. Fig. (2) shows that the model $C_{2 v^{-}}$ symmetric complex 5 possesses seven occupied $\pi$ orbitals. The orbitals $5 b_{1}$ and $7 b_{1}$ describe $\pi$ interactions in the metal fragment without delocalization into the ring. They do not have any contribution from the $\mathrm{C}_{5} \mathrm{H}_{5}{ }^{-}$ligand and thus, they can be neglected for the discussion. The remaining $\pi$ orbitals in the energetic order $4 b_{1}<2 a_{2}<6 b_{1}<3 a_{2}<4 a_{2}$ all have coefficient at the metal atom and at the $\mathrm{C}_{5} \mathrm{H}_{5}{ }^{-}$ligand. This means that the metallacyclic compound $\mathbf{5}$ is actually a $10 \pi$ electron system and therefore, it can be concluded that the $4 n+2$ rule also holds in this type of aromatic compounds.

\section{SUMMARY AND OUTLOOK}

The EDA is a very powerful method for a quantitative estimate of the strength of $\pi$ conjugation in organic, inorganic and organometallic compounds. The advantage of the EDA is that it does not require an external reference system for the calculation of the strength of $\pi$ orbital interactions. The aromatic stabilization energy ASE in cyclic $\pi$ conjugated molecules with respect to acylic systems is then given by the difference between the $\Delta E_{\pi}$ values of the two systems which come from calculations where the fragments of the actual molecules are used as interacting moieties. Since the $\Delta E_{\pi}$ term is part of an energy decomposition scheme where the sum of the energy terms give the experimentally available bond dissociation energy, the calculated values are related to an observable quantity.

\section{ACKNOWLEDGEMENTS}

This work was supported by the Deutsche Forschungsgemeinschaft. Excellent service by the Hochschulrechenzentrum of the Philipps-Universität Marburg is gratefully acknowledged. Further computer time was provided by the HLRS Stuttgart and HHLRZ Darmstadt. I. Fernández is a Ramón y Cajal fellow.

\section{REFERENCES}

(a) For recent reviews about aromaticity see the special issue entitled: Aromaticity in Chem. Rev., 2001, 101. (b) For recent reviews about conjugation and electronic delocalization see the special issue entitled: Delocalization - pi and sigma in Chem. Rev., 2005, 105.

[2] Stanger, A. What is. . aromaticity: a critique of the concept of aromaticity - can it really be defined?. Chem. Comm., 2009, 19391947.

[3] (a) Schleyer, P. v. R. Chem. Rev., 2001, 101, 1115-1117. (b) Jug, K.; Koster, A. M. Aromaticity as a multi-dimensional phenomenon. J. Phys. Org. Chem., 1991, 4, 163-169. (c) Bird, C. W. Absolute hardness as a convenient criterion of heteroaromaticity. Tetrahedron, 1997, 53, 3319-3324. (d) Chesnut, D. B. Differential ring proton NMR shieldings and cyclic stabilization energies. Chem. Phys., 1998, 231, 1-11. (e) Abraham, R. J.; Canton, M.; Reid, M.; Griffiths, L. J. Proton chemical shifts in NMR. Part 14. Proton chemical shifts, ring currents and $\pi$ electron effects in condensed aromatic hydrocarbons and substituted benzenes. J. Chem. Soc. Perkin Trans. 2, 2000, 803-812. (f) Krygowski, T. M.; Cyranski, M. K.; Czarnocki, Z.; Hafelinger, G.; Katritzky, A. R. Aromaticity: a Theoretical Concept of Immense Practical Importance. Tetrahedron, 2000, 56, 1783-1796. (g) Tsipis, C. A.; Karagiannis, E. E.; Kladou, P. F.; Tsipis, A. C. Aromatic Gold and Silver 'Rings': Hydrosilver(I) and Hydrogold(I) Analogues of Aromatic Hydrocarbons. J. Am. Chem. Soc., 2004, 126, 12916-12929. (h) Mills, N. S.; Levy, A.; Plummer, B. F. Antiaromaticity in Fluorenylidene Dications. Experimental and Theoretical Evidence for the Relationship between the HOMO/LUMO Gap and Antiaromaticity. J. Org. Chem., 2004, 69, 6623-6633. (i) Poater, J.; García-Cruz, I.; Illas, F.; Solà, M. Discrepancy between common local aromaticity measures in a series of carbazole derivatives. Phys. Chem. Chem. Phys., 2004, 6, 314-318. (j) Lazzeretti, P. Phys. Chem. Chem. Phys., 2004, 
6, 217-223. (k) Matito, E.; Durán, M.; Solà, M. The aromatic fluctuation index (FLU): A new aromaticity index based on electron delocalization. J. Chem. Phys., 2005, 122, 014109. (1) Bird, C. W. A new aromaticity index and its application to fivemembered ring heterocycles. Tetrahedron, 1985, 41, 1409-1414. (m) Cyranski, M. K.; Krygowski, T. M.; Katritzky, A. R.; Schleyer, P. v. R. To What Extent Can Aromaticity Be Defined Uniquely?. J. Org. Chem., 2002, 67, 1333-1338. (n) P. J. Garratt, Aromaticity, 3rd ed., Wiley, New York, 1986. (o) Minkin, V. I.; Glukhovtsev, M. N.; Simkin, B. Y. Aromaticity and Antiaromaticity: Electronic and Structural Aspects, Wiley, New York, 1994. (p) Schleyer, P. v. R.; Maerker, C.; Dransfeld, A.; Jiao, H.; van Eikema Hommes, N. J. R. Nucleus-Independent Chemical Shifts: A Simple and Efficient Aromaticity Probe. J. Am. Chem. Soc., 1996, 118, 6317-6318.

[4] Feixas, F.; Matito, E.; Poater, J.; and Solà, M. On the performance of some aromaticity indices: A critical assessment using a test set. J. Comput. Chem., 2008, 29, 1543-1554.

[5] Alonso, M.; and Herradón, B. A universal scale of aromaticity for $\pi$-organic compounds. J. Comput. Chem., 2010, 31, 917-928.

[6] Frenking, G.; Krapp, A. Unicorns in the world of chemical bonding models. J. Comput. Chem., 2007, 28, 15-24.

[7] (a) Cappel, D.; Tüllmann, S.; Krapp, A.; Frenking, G. Direct estimate of the conjugative and hyperconjugative stabilization in diynes, dienes, and related compounds. Angew. Chem. Int. Ed., 2005, 44, 3617-3620. (b) Fernández, I.; Frenking, G. Direct estimate of the strength of conjugation and hyperconjugation with the EDA method. Chem. Eur. J., 2006, 12, 3617-3629.

[8] Fernández, I.; Frenking, G. Correlation between Hammett substituent constants and directly calculated $\pi$-conjugation strength. J. Org. Chem., 2006, 71, 2251-2256.

[9] (a) Fernández, I.; Frenking, G. $\pi$-Conjugation in donor-substituted cyanoethynylethenes: an EDA study. Chem. Comm., 2006, 50305032. (b) Fernández, I.; Frenking, G. EDA Study of the $\pi$ conjugation in tunable bis(gem-diethynylethene) fluorophores. $J$. Org. Chem., 2007, 72, 7367-7372.

[10] Moonen, N. N. P.; Pomerantz, W. C.; Gist, R.; Boudon, C.; Gisselbrecht, J.-P.; Kawai, T.; Kishioka, A.; Gross, M.; Irie M.; Diederich, F. Donor-Substituted Cyanoethynylethenes: $\pi$ Conjugation and Band-Gap Tuning in Strong Charge-Transfer Chromophores. Chem. Eur. J., 2005, 11, 3325.

[11] Fernández, I.; Frenking, G. Hyperconjugative stabilization in alkyl carbocations: direct estimate of the $\beta$-effect of group-14 elements. J. Phys. Chem. A, 2007, 111, 8028-8035.

[12] Mo, Y.; Schleyer, P. v. R. An energetic measure of aromaticity and antiaromaticity based on the Pauling-Wheland resonance energies. Chem. Eur. J., 2006, 12, 2009-2020.

[13] For recent reviews of the EDA method and its applications, see: (a) Bickelhaupt, F. M.; Baerends, E. J. in Reviews in Computational Chemistry; K. B. Lipkowitz and D. B. Boyd, Eds.; Wiley-VCH: New York, 2000, Vol. 15, pp. 1-86. (b) Lein, M.; Frenking, G. Theory and Applications of Computational Chemistry: The First 40 Years; Dykstra, C. E., Frenking, G., Kim, K. S., Scuseria, G. E., Eds.; Elsevier: Amsterdam, 2005; p 291. (c) Mitoraj, M. P.; Michalak, M.; Ziegler, T. A combined charge and energy decomposition scheme for bond analysis. J. Chem. Theory Comput., 2009, 5, 962975.

[14] For a further discussion of this, see: (a) Esterhuysen, C.; Frenking, $\mathrm{G}$. The nature of the chemical bond revisited. An energy partitioning analysis of diatomic molecules $\mathrm{E}_{2}(\mathrm{E}=\mathrm{N}-\mathrm{Bi}, \mathrm{F}-\mathrm{I}), \mathrm{CO}$ and $\mathrm{BF}$. Theor. Chem. Acc., 2004, 111, 381-389; Erratum: 2005, 113, 294. (b) Kovács, A.; Esterhuysen, C.; Frenking, G. The nature of the chemical bond revisited: an energy partitioning analysis of nonpolar bonds. Chem. Eur. J., 2005, 11, 1813-1825. (c) Krapp, A.; Bickelhaupt, F. M.; Frenking, G. Orbital overlap and chemical bonding. Chem. Eur. J., 2006, 12, 9196-9216.

[15] (a) Computer code ADF: Baerends, E. J. SCM: Amsterdam, The Netherlands. (b) Guerra, C. F.; Snijders, J. G.; Velde, G. t.; Baerends, E. J. Theor. Chem. Acc., 1998, 99, 391-403. (c) Velde, G. t.; Bickelhaupt, F. M.; Baerends, E. J.; Gisbergen, S. J. A. v.; Guerra,
C. F.; Snijders, J. G.; Ziegler, T. Chemistry with ADF. J. Comput. Chem., 2001, 22, 931-967.

[16] Becke, A. D. Density-functional exchange-energy approximation with correct asymptotic behavior. Phys. Rev. A, 1988, 38, 30983100 .

[17] Perdew, J. P. Density-functional approximation for the correlation energy of the inhomogeneous electron gas. Phys. Rev. B, 1986, 33, 8822-8824.

[18] Snijders, J. G.; Baerends, E. J.; Vernooijs, P. Roothaan-HartreeFock-Slater atomic wave functions: Single-zeta, double-zeta, and extended Slater-type basis sets for ${ }^{87} \mathrm{Fr}-{ }^{103} \mathrm{Lr}$. At. Nucl. Data Tables, 1982, 26, 483-509.

[19] Krijn, J.; Baerends, E. J. Fit Functions in the HFSMethod, Internal Report (in Dutch), Vrije Universiteit Amsterdam, The Netherlands, 1984.

[20] (a) Chang, C.; Pelissier, M.; Durand, P. Regular two-component Pauli-like effective hamiltonians in Dirac theory Phys. Scr., 1986, 34, 394-404. (b) van Lenthe, E.; Baerends, E. J.; Snijders, J. G. Relativistic regular two-component Hamiltonians. J. Chem. Phys., 1993, 99, 4597-4610. (c) van Lenthe, E.; van Leeuwen, R.; Baerends, E. J.; Snijders, J. G. Relativistic regular two-component Hamiltonians. Int. J. Quantum Chem., 1996, 57, 281-293.

[21] Fernández, I.; Frenking, G. Direct estimate of conjugation and aromaticity in cyclic compounds with the EDA method. Faraday Discuss., 2007, 135, 403-421.

[22] Shobe, D. R. Calculations on the group 15 intraring substituted benzenes (pyridine to bismin series) and their datively bonded oxides and sulfides. J. Phys. Chem. A, 2005, 109, 9118-9122.

[23] Wang, Y.; Fernández, I.; Duvall, M.; Wu, J. I.; Li, Q.; Frenking, G.; Schleyer, P. v. R. Consistent Aromaticity Evaluations of Methylenecyclopropene Analogues. J. Org. Chem., 2010, 75, 82528257

[24] (a) Staley, S. W.; Norden, T. D. Synthesis and direct observation of methylenecyclopropane. J. Am. Chem. Soc., 1984, 106, 3699-3670. (b) Billups, W. E.; Lin, L.; Casserley, E. W. Synthesis of methylenecyclopropene. J. Am. Chem. Soc., 1984, 106, 3698-3699. (c) Maier, G.; Hoppe, M.; Lanz, K.; Reisenauer, P. Neue Wege zum Cyclobutadien und Methylencyclopropen. Tetrahedron Lett., 1984, 25, 5645-5648.

[25] (a) Burk, P.; Abboud, J. L. M.; Koppel, I. A. Aromaticity of substituted cyclopropenes: a theoretical study. J. Phys. Chem., 1996, 100 6992-6997. (b) Bachrach, S. M. The resonance energy of methylenecyclopropene and cyclopropenone. J. Org. Chem., 1990, 55, 4961-4963. (c) Bachrach, S. M.; Liu, M. Structure, topological electron density analysis and aromaticity of 4-heterosubstituted methylenecyclopropenes: $\mathrm{CH}_{2}, \mathrm{NH}, \mathrm{O}, \mathrm{SiH}_{2}, \mathrm{PH}$ and S. J. Phys. Org. Chem., 1991, 4, 242-250. (d) Manatt, S. L.; Roberts, J. D. Small-ring compounds. XXIV. Molecular orbital calculations of the delocalization energies of some small-Ring systems. J. Org. Chem., 1959, 24, 1336-1338. (e) Roberts, J. D.; Streitwieser, A.; Rega, C. M. Small-Ring compounds. X. Molecular orbital calculations of properties of some small-Ring hydrocarbons and free radicals. J. Am. Chem. Soc., 1952, 74, 4579-4582.

[26] (a) Billups, W. E.; McCord, D. J. Gas-phase synthesis of reactive molecules using adsorbed reagents. Angew. Chem. Int. Ed., 1994 33, 1332-1343. (b) Norden, T. D.; Staley, S. W.; Taylor, W. H.; Harmony, M. D. Electronic character of methylenecyclopropene: microwave spectrum, structure, and dipole moment. J. Am. Chem. Soc., 1986, 108, 7912-7918. (c) Hess, B. A., Jr.; Michalska, D.; Schaad, L. Ab initio study of the infrared spectrum of methylenecyclopropene. J. Am. Chem. Soc., 1985, 107, 1449-1450. (d) Staley, S. W.; Norden, T. D.; Taylor, W. H.; Harmony, M. D. Electronic structure of cyclopropenone and its relationship to methylenecyclopropene. Evaluation of criteria for aromaticity. J. Am. Chem. Soc., 1987, 109, 7641-7647.

[27] Thorn, D. L.; Hoffmann, R. Delocalization in Metallabenzenes. Nouv. J. Chim., 1979, 3, 39-45.

[28] Elliot, G. P.; Roper, W. R.; Waters, J. M. Metallacyclohexatrienes or 'metallabenzenes.' Synthesis of osmabenzene derivatives and X- 
ray crystal structure of $\left[\mathrm{Os}(\mathrm{CSCHCHCHCH})(\mathrm{CO})\left(\mathrm{PPh}_{3}\right)_{2}\right] . \quad J$. Chem. Soc., Chem. Comm., 1982, 811.

[29] For recent reviews, see: (a) Bleeke, J. R. Metallabenzenes. Chem. Rev., 2001, 101, 1205-1228. (b) He, G.; Xia, H.; Jia, G. Studies of Metallabenzenes. Chin. Sci. Bull., 2004, 49, 1543-1553. (c) Wright, L. J. Metallabenzenes and metallabenzenoids. Dalton Trans., 2006, 1821-1827. (d) Landorf, W. C.; Haley, M. M. Angew. Chem. Int. $E d .$, 2006, 45, 3914, and references therein.
[30] (a) Chamizo, J. A.; Morgado, J.; Sosa, P. Organometallic aromaticity. Organometallics, 1993, 12, 5005. (b) Iron, M. A.; Lucassen, A. C. B.; Cohen, H.; van der Boom, M. E.; Martin, J. M. L. A computational foray into the formation and reactivity of metallabenzenes. J. Am. Chem. Soc., 2004, 126, 11699-11710. (c) De Proft, F.; Geerlings, P. Relative hardness as a measure of aromaticity. Phys. Chem. Chem. Phys., 2004, 6, 242.

[31] Fernández, I.; Frenking, G. Aromaticity in Metallabenzenes. Chem. Eur. J., 2007, 13, 5873-5884.

(c) Fernández and Frenking; Licensee Bentham Open.

This is an open access article licensed under the terms of the Creative Commons Attribution Non-Commercial License (http://creativecommons.org/licenses/by-nc/3.0/) which permits unrestricted, non-commercial use, distribution and reproduction in any medium, provided the work is properly cited. 